\title{
Modification of the Maxilla Axial Cut for Tomographic Evaluation of Midpalatal Suture Maturation
}

\section{Modificação do Corte Axial da Maxila para Avaliação Tomográfica da Maturação da Sutura Palatina Mediana}

\author{
Luiz Fernando Tadano Miguita ${ }^{a}$; Ana Claudia de Castro Ferreira Contib; Renata Rodrigues Almeida-Pedrin*b; Fábio \\ Pinto Guedes; ; Diego Luiz Tonelloc; Graziela Hernandes Volpato ${ }^{\text {b }}$, Leopoldino Capelozza-Filhoc
}

\author{
${ }^{a}$ Unisagrado, Orthodontic Department. SP, Brazil. \\ ${ }^{b}$ Unopar, Orthodontic Department. PR. Brazil \\ 'University of São Paulo, Bauru Dental School. SP, Brazil. \\ *E-mail: renata.pedrin@kroton.com.br \\ Recebido em: 02/03/2020 \\ Aprovado em: 02/06/2020
}

\begin{abstract}
This study aimed at modifying the method for obtaining an axial cut of the maxilla, considering the palatine anatomy, for evaluation of the maturation stage of the midpalatal suture (MPS) and to compare this modified method with the original one.The sample consisted of 84 conebeam computed tomography (CBCT) scans of 40 boys and 44 girls, aged 11 to 15 years. The files were exported to the Nemotec Dental Studio program, which was used to obtain axial cuts of the maxilla so as to follow the palatine anatomy, keeping the buccal and nasal cortical bones centralized and equidistant. Two previously calibrated evaluators classified the axial images of the MPS into 5 maturational stages (A, B, C, D, and E) according to suture morphology. Kappa test was used to test intra and inter-examiner agreement and the sign test was used to compare the results of this study with those from the original method. Statistical significance level was set at $0.05 \%$. The kappa values for intra and inter-examiner agreement were 0.88 and 0.69 , respectively. The modified method was able to evaluate the MPS maturation status and could demonstrate stages of maturation in more detail than the original method. Classification of the MPS maturation with the curved suture axial cut of this method is similar to the original method, with the advantage of allowing evaluation of maturation in the midline of the palate, even when the palate was curved and/or thick.
\end{abstract}

Keywords: Sutures. Maxilla. Palatal Expansion Technique.

\section{Resumo}

Este estudo visou modificar o método para a obtenção de um corte axial da maxila, considerando a anatomia do palato, para avaliação da maturação da sutura palatina (SPM) e para comparar este método modificado com o original. A amostra foi composta de 84 tomografias computadorizadas (TCFC) de 40 meninos e 44 meninas, com idades entre 11 a 15 anos. Os arquivos foram exportados para o programa Nemotec Dental Studio, que foi usado para obter cortes axiais da maxila de modo a acompanhar a anatomia do palato, mantendo a cortical óssea vestibular e nasal centralizada e equidistante. Dois avaliadores previamente calibrados, classificaram as imagens axiais da SPM em 5 fases de maturação $(A, B, C, D$, e E) de acordo com a morfologia da sutura. O Teste Kappa foi usado para testar concordância intra e inter-examinador e o teste do sinal foi utilizado para comparar os resultados deste estudo com os do método original. O nivel de significância estatística foi de 0,05\%. Os valores de kappa para concordância intra e inter-examinador foram 0,88 e 0,69, respectivamente. O método modificado foi capaz de avaliar o estágio de maturação da SPM e pode demonstrar estágios de maturação em mais detalhe do que o método original. A classificação da maturação da SPM com o corte axial curvo deste método é semelhante ao método original, com a vantagem de permitir a avaliação da maturação na linha média do palato, mesmo quando o palato for curvo elou espesso.

Palavras-chave: Suturas. Maxila. Técnica de Expansão Palatina.

\section{Introduction}

The rapid maxillary expansion (RME) protocol can separate the maxillary bones to correct their transverse dimension. ${ }^{1,2}$ The high indication rate for RME has prompted orthodontists to expand their knowledge about the midpalatal suture (MPS), ${ }^{3,4}$ its physiology and methods of evaluation the age or bone maturation stage at which the prognosis of RME becomes unfavorable. ${ }^{3-6}$

The prognosis of maxillary disjunction has been supported by some clinical evidence, but the exact correlation between morphological and/or chronological parameters have still remained unclear. Although It has been reported that stenosis of the MPS advances progressively with age, variability of this process in relation to age, gender and skeletal status may happens. ${ }^{3,7}$ After fusion of the palatine and maxillary bones, RME attempt can result in excessive pain, buccal inclination of the alveolar process, palatal lesions, and even failure of the expansion.

There is therefore a need for tests that can appropriately define an individual's prognosis for RME outcomes. ${ }^{4,8,9}$ Thus, a method based on the sutural morphology has been proposed, ${ }^{4}$ although its applicability would be compromised by variations in the curvature and thickness of the palate. ${ }^{10,11}$ In this method cone-beam computed tomography (CBCT) scans are applied in order to classify the MPS stage of maturation, and it seems to correlate well with clinical reports. ${ }^{4,10-12}$ Nevertheless, some 
controversies still remain and require clarification.

Recently, a study evaluated the reliability and usefulness of the method of classification of midpalatal suture maturation proposed by Angelieri et al. ${ }^{4}$ to predict success of rapid maxillary expansion (RME). The authors found no interexaminer agreement in the reliability test, affected by the necessary examiner calibration and the degree of sharpness and clarity of the post-acquisition image. ${ }^{13}$

Thus, in this study, we modified the method proposed by Angelieri et al. ${ }^{4}$ to obtain the axial plane of the MPS and determine its degree of maturation. Modifications were made using a curved axial cut of the maxilla that was equidistant from the buccal and nasal cortical bones, so that sutural maturation was assessed at the same level throughout its length. We also aimed at comparing the findings obtained by the original method with ours to better support clinical evidence on distribution of stages and a more solid prediction of RME prognosis.

\section{Material and Methods}

This research was approved by the ethics committee under protocol number 2.076.299. The subjects in this retrospective study was the same as in the study by Tonello et al. ${ }^{10}$ These individuals already had undergone tomographic examination for the diagnosis of retained teeth.

A total of 84 CBCT scans (from 44 females and 40 males) was included in the study. The CT scans were obtained in a private clinic with the iCat tomographer (Imaging Sciences International, Hastfield, PA, USA), with the following setting: scan time, 8.9 to 30 seconds, field of view of at least $11 \mathrm{~cm}$, and voxel size of $0.2-0.3 \mathrm{~mm}$. The patients remained seated, with the head positioned with the Frankfurt plane parallel to the ground and the median sagittal plane perpendicular to the ground.

The inclusion criteria were individuals aged between 11 and 15 years, who underwent CBCT imaging, with no history of orthodontic treatment including maxillary expansion, nonsyndromic and with no cleft lip and/or palate.

The CBCT images, in Digital Imaging and Communication in Medicine format, were converted to the ".nmv" extension, a specific format used for manipulation in the Nemotec Viewer program (Nemotec Dental Studio, Nemotec, Madrid, Spain).

Initially, the tomographic volume was moved until the sagittal plane was visualized in the window for the axial plane, where panoramic tracing was performed to obtain the axial cut of the median palatine suture. On the multiplanar reconstruction screen, the reference lines (orange lines, Figure 1) were centralized in the midline of the palate, in the coronal and axial cuts; in order to define the central region of the palate.

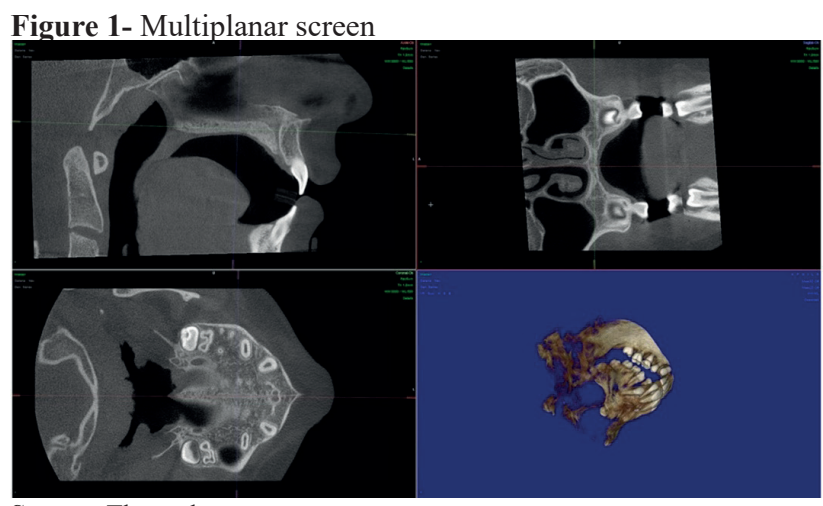

Source: The authors.

Anatomical references were used to standardize the axial cut of the maxilla. Halfway between the posterior nasal spine (PNS) and the posterior wall of the incisive foramen, the thickness of the palate was divided between the buccal and nasal cortical bones and the vertical midpoint of the palate was obtained.

The cut began in the PNS and proceeded, equidistantly, from the upper and lower cortical bones of the palatine process, passing through the midpoint of the palate, to reach point A of the maxilla. The axial cut of the maxilla, which follows the palatine anatomy and remains in the center of the palate vertically, was thus defined (Figures 2A and B).

Figure 2- (A) sagittal cut of the maxilla demonstrating the curved line along the midpalatal suture to obtain the axial cut (flexible); (B) Axial cut of the maxilla proposed by our study

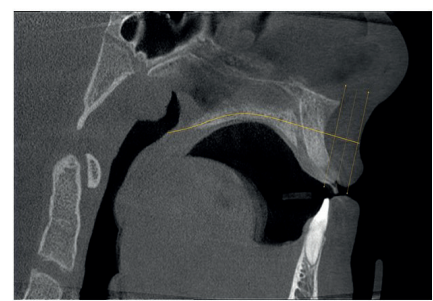

2(A)

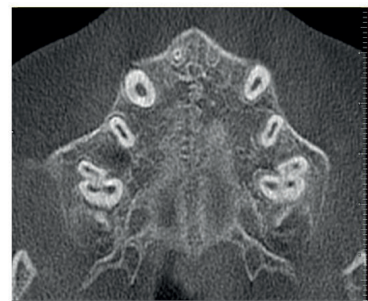

2(B)
Source: The authors.

The images of the axial cuts were exported as JPEG files and organized at random into four PowerPoint presentations (PowerPoint for Mac 2011; Microsoft, Redmond, WA, USA), with a black background, each comprising 21 images. The images were identified with number only.

These images were then evaluated blindly by two previously calibrated evaluators (LFTM and FG), with an interval of 24 hours between presentations to prevent fatigue. The results were compared and those that did not agree were reevaluated together to achieve final consensus. To classify, the evaluators used morphological parameters described in previous studies. ${ }^{4,10,12}$

The ability to accompany the palatine anatomy and maintain equidistance from the buccal and nasal cortical bones are the main characteristics that distinguish this proposed method from the original method published. ${ }^{4}$ To demonstrate these differences, the sagittal and axial cuts of a same patient 
are shown in Figures 2 and 3.

Figure 3- (A) Sagittal cut of the anterior region of the maxilla; (B) sagittal cut of the posterior region of the maxilla; (C) axial cut of the maxilla (anterior); (D) axial cut of the maxilla (posterior) according to the method proposed by Angelieri et al. (2013)

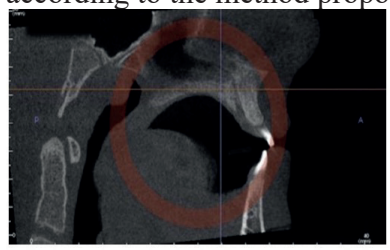

$3(\mathrm{~A})$
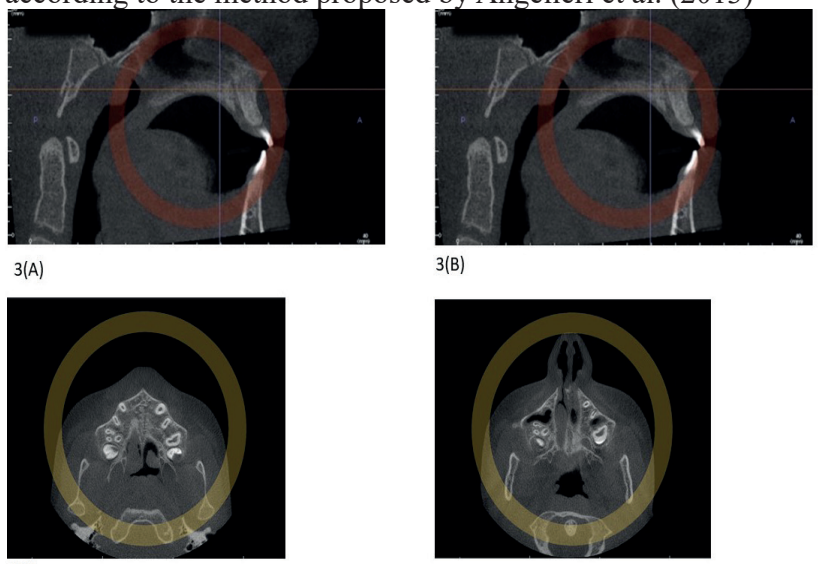

3(c)

Source: The authors
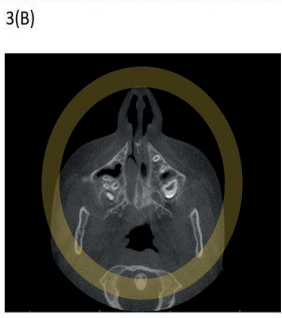

3(D)

To verify the reliability of the method used to classify the palatine suture maturation "status", all images were again evaluated by a second examiner (FG), to obtain the interexaminer error, and 42 images were again evaluated after 30 days by the first evaluator to determine intra-examiner error.
The measurement error was evaluated by kappa statistics and the result interpreted according to Landis and Koch. ${ }^{14}$

This study's results were compared with the results of Tonello et al. ${ }^{10}$. The sample and the second evaluator (FG) were the same in both studies.

\subsection{Statistical analysis}

The data obtained in this study were described using absolute (n) and relative (\%) frequency. To compare these results with those of Tonello et al. ${ }^{10}$ the sign test was used. Kappa test was used to test intra and inter-examiner agreement. A significance level of 5\% was adopted in all statistical tests.

All statistical analyses were performed in Statistica software (version 13; StatSoft, Tulsa, OK, USA).

\section{Results and Discussion}

The inter-examiner kappa value obtained was 0.69 (substantial) and the intra-examiner was 0.88 (almost-perfect).

According to Tables 1 and 2, no individual was classified as Stage A. Stage B was present at all ages, except for individuals aged 14 years. The prevalence of this stage at younger ages, i.e., 11 to 13 years, was $17 \%$, and for individuals aged more than 14 years and up to 15 years, it was $6.5 \%$. These data confirmed the influence of age on the maturation of the MPS.

Table 1 - Distribution of the maturational stages by age and gender

\begin{tabular}{|c|c|c|c|c|c|c|c|c|c|c|c|c|}
\hline \multirow{3}{*}{$\begin{array}{c}\text { Age } \\
\text { (years) }\end{array}$} & \multirow{3}{*}{ Gender } & \multicolumn{10}{|c|}{ Stage } & \multirow{3}{*}{ Total } \\
\hline & & \multicolumn{2}{|c|}{$\mathbf{A}$} & \multicolumn{2}{|c|}{ B } & \multicolumn{2}{|c|}{ C } & \multicolumn{2}{|c|}{ D } & \multicolumn{2}{|c|}{$\mathbf{E}$} & \\
\hline & & $\mathbf{n}$ & $\%$ & $\mathbf{n}$ & $\%$ & $\mathbf{N}$ & $\%$ & n & $\%$ & $\mathbf{n}$ & $\%$ & \\
\hline \multirow{3}{*}{11} & $\mathrm{~F}$ & - & - & 2 & 20,0 & 5 & 50,0 & 3 & 30,0 & 0 & 0,0 & 10 \\
\hline & M & - & - & 0 & 0,0 & 3 & 100,0 & 0 & 0,0 & 0 & 0,0 & 3 \\
\hline & $\mathrm{F}+\mathrm{M}$ & - & - & 2 & 15,4 & 8 & 61,5 & 3 & 23,1 & 0 & 0,0 & 13 \\
\hline \multirow{3}{*}{12} & $\mathrm{~F}$ & - & - & 3 & 16,7 & 11 & 61,1 & 3 & 16,7 & 1 & 5,5 & 18 \\
\hline & M & - & - & 2 & 22,2 & 5 & 55,6 & 1 & 11,1 & 1 & 11,1 & 9 \\
\hline & $\mathrm{F}+\mathrm{M}$ & - & - & 5 & 18,5 & 16 & 59,3 & 4 & 14,8 & 2 & 7,4 & 27 \\
\hline \multirow{3}{*}{13} & $\mathrm{~F}$ & - & - & 0 & 0,0 & 1 & 50,0 & 1 & 50,0 & 0 & 0,00 & 2 \\
\hline & M & - & - & 2 & 18,2 & 5 & 45,6 & 2 & 18,2 & 2 & 18,2 & 11 \\
\hline & $\mathrm{F}+\mathrm{M}$ & - & - & 2 & 15,4 & 6 & 46,1 & 3 & 23,1 & 2 & 15,4 & 13 \\
\hline \multirow{3}{*}{14} & $\mathrm{~F}$ & - & - & 0 & 0,0 & 4 & 50,0 & 1 & 12,5 & 3 & 37,5 & 8 \\
\hline & M & - & - & 0 & 0,0 & 2 & 28,6 & 3 & 42,8 & 2 & 28,6 & 7 \\
\hline & $\mathrm{F}+\mathrm{M}$ & - & - & 0 & 0,0 & 6 & 40,0 & 4 & 26,7 & 5 & 33,3 & 15 \\
\hline \multirow{3}{*}{15} & $\mathrm{~F}$ & - & - & 1 & 16,7 & 4 & 66,6 & 0 & 0,0 & 1 & 16,7 & 6 \\
\hline & M & - & - & 1 & 10,0 & 5 & 50,0 & 3 & 30,0 & 1 & 10,0 & 10 \\
\hline & $\mathrm{F}+\mathrm{M}$ & - & - & 2 & 12,5 & 9 & 56,3 & 3 & 18,8 & 2 & 12,5 & 16 \\
\hline \multirow{3}{*}{$11-15$} & $\mathrm{~F}$ & - & - & 6 & 13,6 & 25 & 56,8 & 8 & 18,2 & 5 & 11,7 & 44 \\
\hline & M & - & - & 5 & 12,5 & 20 & 50,0 & 9 & 22,5 & 6 & 15,0 & 40 \\
\hline & $\mathrm{F}+\mathrm{M}$ & - & - & 11 & 13,1 & 45 & 53,6 & 17 & 20,2 & 11 & 13,1 & 84 \\
\hline
\end{tabular}


Table 2 - Description of the classifications obtained by age range and gender

\begin{tabular}{|c|c|c|c|c|c|c|c|c|c|c|c|c|}
\hline \multirow{3}{*}{$\begin{array}{c}\text { Age } \\
\text { (years) }\end{array}$} & \multirow{3}{*}{ Gender } & \multicolumn{10}{|c|}{ Stage } & \multirow{3}{*}{ Tota } \\
\hline & & \multicolumn{2}{|c|}{$\mathbf{A}$} & \multicolumn{2}{|c|}{ B } & \multicolumn{2}{|c|}{$\mathrm{C}$} & \multicolumn{2}{|c|}{ D } & \multicolumn{2}{|c|}{$\mathbf{E}$} & \\
\hline & & $\mathbf{n}$ & $\%$ & $\mathbf{n}$ & $\%$ & $\mathbf{N}$ & $\%$ & $\mathbf{n}$ & $\%$ & $\mathbf{n}$ & $\%$ & \\
\hline \multirow{3}{*}{$11-13$} & $\mathrm{~F}$ & - & - & 5 & 16,7 & 17 & 56,7 & 7 & 23,3 & 1 & 3,3 & 30 \\
\hline & M & - & - & 4 & 17,4 & 13 & 56,5 & 3 & 13,0 & 3 & 13,0 & 23 \\
\hline & $\mathrm{F}+\mathrm{M}$ & - & - & 9 & 17,0 & 30 & 56,6 & 10 & 18,9 & 4 & 7,5 & 53 \\
\hline \multirow{3}{*}{ 14-15 } & $\mathrm{F}$ & - & - & 1 & 7,1 & 8 & 57,1 & 1 & 7,1 & 4 & 28,6 & 14 \\
\hline & M & - & - & 1 & 5,9 & 7 & 41,2 & 6 & 35,3 & 3 & 17,6 & 17 \\
\hline & $\mathrm{F}+\mathrm{M}$ & - & - & 2 & 6,5 & 15 & 48,4 & 7 & 22,6 & 7 & 22,6 & 31 \\
\hline
\end{tabular}

F, Female; M, Male.

Source: Research data.

Stage $\mathrm{C}$ was the most prevalent at all ages (11 years: $61.5 \%$; 12 years: $59.3 \%$; 13 years: $46.1 \%$; 14 years: $40 \%$; and 15 years: $56.3 \%$ ), and accounted for $53.6 \%$ of the sample and $56.8 \%$ of females.

For girls, Stage D was prevalent in the range of 11 to 13 years, reaching $30 \%$ at 11 years; however, this stage was prevalent among boys in the range of 14 to 15 years.

We also classified individuals into two age ranges (1113 years and $14-15$ years). Stage $C$ continued to be the most prevalent; however, the prevalence of Stages D and E increased in the 14-15-year-old group.

When the results were compared with the study by Tonello et al. ${ }^{10}$ agreement was observed in 43 of the 84 images (Table $3)$.

Table 3 - Frequencies of classification of midpalatal suture maturation stage on cone-beam computed tomography scans according to the present study and Tonello et al..$^{14}$

\begin{tabular}{|c|c|c|c|c|c|c|}
\hline \multirow{2}{*}{ Classification } & \multicolumn{5}{|c|}{ Tonello et al. (2017) } & \multirow{2}{*}{ Total } \\
\cline { 2 - 6 } & A & B & C & D & E & \\
\hline A & 0 & 0 & 0 & 0 & 0 & 0 \\
\hline B & 1 & 7 & 2 & 0 & 1 & 11 \\
\hline C & 0 & 8 & 29 & 4 & 4 & 45 \\
\hline D & 0 & 4 & 8 & 4 & 1 & 17 \\
\hline E & 0 & 2 & 3 & 3 & 3 & 11 \\
\hline Total & 1 & 21 & 42 & 11 & 9 & 84 \\
\hline
\end{tabular}

Source: Research data.

In terms of differences, in most cases of discrepant classification, the difference involved a single stage; in particular, seven individuals were classified in earlier stages and 20 individuals in later stages. This tendency for scoring classifications higher than those determined by Tonello et al. ${ }^{10}$ is shown in Table 4, and was significantly different according to the sign test. Most discrepancies were found in the intermediate stages, closer to the period of transition from an open to a closed suture (Stages B, C, and D).
Table 4 - Disagreement in classifications of midpalatal suture maturation stage on cone-beam computed tomography scans in the present study from those of Tonello et al. ${ }^{14}$

\begin{tabular}{|c|c|c|}
\hline Disagreement & $\mathbf{N}$ & $\mathbf{\%}$ \\
\hline Below & 12 & $14.3 \%$ \\
\hline Equal & 43 & $51.2 \%$ \\
\hline Above & 29 & $34.5 \%$ \\
\hline
\end{tabular}

Sign test: $p=0.012^{*}$ (statistically significant)

Source: Research data.

Skeletal development and age are reportedly important, but not definitive factors related to the maturation stage of the MPS. ${ }^{4,8,10,11,15}$ Although the prognosis of RME outcome worsens with age, there is no consensus regarding the age limit for performing this. ${ }^{4,8,12,16}$ The lack of an appropriate individualized diagnostic test doubts over the variability of the MPS maturation process. ${ }^{16}$ Based on already reported statement regarding variations in the curvature and thickness of the palate in the method proposed by Angelieri et al. ${ }^{4}$ which could jeopardize its results, we proposed a new way to obtain the axial maxilla cut. The axial cut proposed was obtained from a curved line representing the suture in the sagittal plane, equidistant from the buccal and nasal cortical bones, so that sutural maturation could be assessed at the same level throughout its length.

To compare the original and modified methods, we compared the results of the current study directly with those of Tonello et al..$^{10}$ who used the same sample of our study (Table 3). In $51.2 \%$ of this sample, the classification of MPS maturation stage was identical between the studies, and the extreme stages did not show much difference between the methods. The only individual classified in Stage A by Tonello et al. ${ }^{10}$ was classified as stage B in the present study. In Stage E, Tonello et al. ${ }^{10}$ found nine individuals, while we found 11. Interestingly, eight of the 11 individuals in Stage $\mathrm{E}$ had a narrower palate than the rest of the sample, as also reported by Tonello et al. ${ }^{10} \mathrm{e}$ Angelieri et al. ${ }^{4}$ pointed out that, in general, patients with this characteristic are classified as Stage E, due to the proximity between the cortical bones and the reduction 
in the MPS maturation time. From this perspective, when relatively young individuals are classified as Stage E, it may suggest that RME protocol could present limited success.

In young patients in this study, a favorable prognosis for RME was confirmed in $66.7 \%$ of individuals who were in maturation stages in which the suture had not yet fused. This number, however, was lower than the $76.2 \%$ found. ${ }^{10}$ When comparing the more advanced stages at an early age (11 to 13 years), Tonello et al. ${ }^{10}$ reported that $7.7 \%$ of individuals were at Stage D and $1.9 \%$ at Stage E, while we found these frequencies to be $18.9 \%$ and $7.5 \%$, respectively, showing more advanced stages of MPS maturation or "aging" in terms of MPS maturation status. Both methods indicated that Stages $\mathrm{D}$ and $\mathrm{E}$ increased in the age range of 14 to 15 years, and that there is sexual dimorphism in the sutural maturation stages as well as in growth. In the range of 11 to 13 years, Tonello et al. ${ }^{10}$ found Stage E mostly present in girls; while in Stage D, there were twice as many girls as boys. These data confirmed early sutural maturation in girls; this difference between the sexes does not seem to be present in adulthood. ${ }^{4}$

Gender was not influential in the maturational variability of MPS in patients over 18 years of age. Studies that evaluated palatine density showed similarities for gender up to 50 years of age and a decrease in density in women after this. ${ }^{12,17}$ Divergence in classifications between the present study and Tonello et al. ${ }^{10}$ mostly occurred in the transition phase from open to closed suture. Tonello et al. ${ }^{10}$ classified 21 individuals in Stage B and 11 in Stage D, while in this research, these stages were present in 11 and 17 individuals, respectively. This emphasized that the modified method allowed more advanced diagnosis of the maturation stages (Table 3). This trend was evidenced by classifications identical to, or below, or above $\left(43,12\right.$, and 29 , respectively) those of Tonello et al. ${ }^{10}$ (Table 4). These results suggest that, in palates with a small curvature, the original method (involving a linear cut) places the cut in a "higher" region, that is, further away from the cortical buccal region than the method proposed in this study (involving a cut that remains equidistant from the cortical bones). Considering the order of ossification described in the literature ${ }^{8}$ this may result in an earlier maturation stage classification.

On the other hand, when evaluating the palatine anatomy of the 12 individuals who had a reduced maturation stage classification in this study, as compared to that of Tonello et al. ${ }^{10}$ we observed that those authors performed more than one axial cut in 10 of these 12 patients, due to the greater curvature and/or thickness of the palate, while we used only a single cut. These results seem to be more consistent and indicate that the proposed methodology is a viable alternative, especially in the presence of anatomic variation, such as excessive curvature, which could require two traces to define the palate's midline. Thus, evaluating a single image could be advantageous over classifying a stage by using two images. Aging of the stages does not seem to be due to the inefficiency of the method, but rather due to inadequacy of the stages.

Stage C, compatible with the period of adolescence is a phase in which the sutural maturation presents the most remarkable interdigitations and calcification "islets" are visible. ${ }^{15}$ From a prognostic point of view, this appears to be the limiting stage of maturation for obtaining favorable outcomes when performing RME with conventional method., ${ }^{4,10,11}$ This seems to be a reasonable conclusion, based on the abundant clinical description in literature, in which the limit correlates with age..$^{3,417-19}$ In the present study, we found that $53.6 \%$ of individuals belonged to Stage C, while Tonello et al. ${ }^{10}$ defined this figure as $50 \%$, confirming the prevalence of Stage C. In patients aged 16 to 20 years, the prevalence of stage $\mathrm{C}$ was also high, around $44.5 \%$. It seems unlikely that a patient aged 20 years, in Stage $C$, would have the same prognosis for RME, in terms of quantity and especially quality, as an 11-year old patient. ${ }^{4,17,19}$

Considering the histological data, the long period in which Stage C remains prevalent seems to be related to a disregard for the importance of the palatine bone in the definition of changes in prognosis with this method. Stage $\mathrm{C}$ is likely to be maintained for a long period of time, because the maturation process in this stage is not divided for the posterior portion of the suture (palatine bones) and the middle portion (maxillary bones up to the incisive foramen). Thus, Stage $\mathrm{C}$ is used to describe the same sutural status in $2 / 3$ of the palatine area, starting from the PNS up to the incisive foramen, which seems inappropriate since the ossification process progresses from the posterior to the anterior region, at a rate that varies among individuals, and that could take a very long time. ${ }^{8}$

According to our results, the discrepancy between age and maturation process may not be solved, as the stages were considered more mature. The evaluation of MPS maturation "status" at the midpoint of the suture may not resolve the conflict between the prognosis indicated by the method and that defined by well-documented clinical practice On the other hand, as the anatomy of the palate was taken into consideration (which was the primary goal), the method seems appropriate and should be used in cases with curved and/or thick palates. It also should be highlighted that one should consider dividing stage $\mathrm{C}$, taking into account the maturation process along the suture, in order to better define the status for the RME prognosis.

\section{Conclusion}

This modified method allowed classification of the MPS maturation status based of the evaluation in the midline of the palate, especially when the palate is very curved and/or thick.

- The maturation stages were identified as being more mature than those defined by the original method.

- The prognosis of the outcome of RME is still dependent on clinical studies. 


\section{References}

1. Haas AJ. Rapid expansion of the maxillary dental arch and nasal cavity by opening the mid palatal suture. Angle Orthod 1961;31(2):73-90. doi: https://doi.org/10.1043/00033219(1961)031<0073:REOTMD > 2.0.CO;2

2. Haas AJ. The treatment of maxillary deficiency by opening the midpalatal suture. Angle Orthod 1965;35(1):200-17. doi: https://doi.org/10.1043/0003-3219(1965)035<0200:TTOMD $\mathrm{B}>2.0 . \mathrm{CO} ; 2$

3. Baccetti T, Franchi L, Cameron CG, McNamara JA. Treatment timing for rapid maxillary expansion. Angle Orthod 2001;71(5):343-50. doi: 10.1043/0003-3219(2001)071<0343:TTFRME $>2.0$. CO;2

4. Angelieri F, Cevidanes LHS, Franchi L, Gonçalves JR, Benavides E, Mcnamara Jr JA. Midpalatal suture maturation: classification method for individual assessment before rapid maxillary expansion. Am J Orthod Dentofacial Orthop 2013;144(5):759-69. doi: 10.1016/j.ajodo.2013.04.022

5. Acar YB, Motro M, Erverdi AN. Hounsfield Units: A new indicator showing maxillary resistance in rapid maxillary expansion cases? Angle Orthod 2015;85(1):109-16. doi: https://doi.org/10.2319/111013-823.1

6. Grunheid T, Larson CE, Larson BE. Midpalatal suture density ratio: A novel predictor of skeletal response to rapid maxillary expansion. Am J Orthod Dentofacial Orthop 2017;151(2):26776. doi: https://doi.org/10.1016/j.ajodo.2016.06.043

7. Werhbain H, Yildizhan F. The mid-palatal suture in young adults. A radiological-histological investigation. Eur J Orthod 2001;23(2):105-14. doi: https://doi.org/10.1093/ejo/23.2.105

8. Persson M, Thilander B. Palatal suture closure in man from 15 to 35 years of age. Am J Orthod 1977;72(1):42-52. doi: https://doi.org/10.1016/0002-9416(77)90123-3

9. Capelozza Filho L, Cardoso Neto J, Silva Filho OG, Ursi WJS. Non-surgically assisted rapid maxillary expansion in adults. Int J Adult Orthod Orthognath Surg 1996;11(1):57-66.

10. Tonello DL, Ladewig VM, Guedes FP, Conti ACCF, AlmeidaPedrin RR, Capelozza-Filho L. Midpalatal suture maturation in 11 to 15 years old subject: a cone-bean tomographic study. Am J Orthod Dentofacial Orthop 2017;152(1):42-8. doi: https://doi.org/10.1016/j.ajodo.2016.11.028

11. Ladewig VM, Guedes FP, Capelozza-Filho L, Cardoso MA, Almeida-Pedrin RR, Conti ACCF. Tomographic evaluation of the maturation stage of the midpalatal suture in post-adolescents. Am J Orthod Dentofacial Orthop 2018;153(6):818-24. doi: https://doi.org/10.1016/j. ajodo.2017.09.019

12. Angelieri F, Franchi L, Cevidanes LHS, Gonçalves JR, Niei M, Wolford LM, McNamara Jr JA. Cone beam computed tomography evaluation of midpalatal suture maturation in adults. Int. J Oral Maxillofac Surg 2017;46(12):1557-61. doi: https://doi.org/10.1016/j.ijom.2017.06.021

13. Isfeld D, Flores-Mir C, Leon-Salazar V, Lagrav`ere M. Evaluation of a novel palatal suture maturation classification as assessed by cone-beam computed tomography imaging of a pre- and postexpansion treatment cohort. Angle Orthod 2019;89(2):252-61. doi: https://doi.org/10.2319/040518258.1

14. Landis J, Kock GG. The measurement of observer agreement for categorical data. Biometrics. 1977;33(1):159-74. doi: $10.2307 / 2529310$

15. Melsen B. Palatal growth studied on human autopsy material: A histologic microradiographic study. Am J Orthod 1975;68(1):42-54. doi: 10.1016/0002-9416(75)90158-x

16. Lee KJ, Park YC, Park JY, Hwang WS. Miniscrew-assisted nonsurgical palatal expansion before orthognathic surgery for a patient with severe mandibular prognathism. Am J Orthod Dentofacial Orthop 2010;137(6):830-9. doi: https://doi. org/10.1016/j.ajodo.2007.10.065

17. Alpern MC, Yurosko JJ. Rapid palatal expansion in adults with and without surgery. Angle Orthod 1987;57(3):245-63. doi: https://doi.org/10.1043/0003-3219(1987)057<0245:RPE $\mathrm{IA}>2.0 . \mathrm{CO} ; 2$

18. Revelo B, Fishman LS. Maturational evaluation of ossification of the midpalatal suture. Am J Orthod Dentofacial Orthop 1994;105(3):288-92. doi: https://doi.org/10.1016/S08895406(94)70123-7

19. Bishara SE, Staley RN. Maxillary expansion: clinical implications. Am J Orthod Dentofacial Orthop 1987;91(1):314. doi: 10.1016/0889-5406(87)90202-2 